\title{
Covid-19: A Tsunami That Amplifies Existing Trends in Demographic Research
}

Emilio Zagheni

Follow this and additional works at: https://knowledgecommons.popcouncil.org/series_pdr_essays-covid How does access to this work benefit you? Let us know!

\section{Recommended Citation}

Zagheni, Emilio. "Covid-19: A Tsunami That Amplifies Existing Trends in Demographic Research." In Covid-19 and the Global Demographic Research Agenda, edited by Landis MacKellar and Rachel Friedman, 77-82. New York: Population Council, 2021. 


\title{
Covid-19: A Tsunami That Amplifies Existing Trends in Demographic Research
}

\author{
EMILIO ZAGHENI
}

WHILE DIFFERENT WAVES of Covid-19 have reached different shores at different times, and the intensity of the consequences have been felt unequally, everyone has been affected in some ways. The pandemic has been a major public health crisis, but the long-lasting effects of this disruptive force will also touch upon many more aspects of our lives and reshape priorities for research. During crises, some commonly held beliefs are questioned and scrutinized. While core principles weather the storm, opportunities to build new and better infrastructure and practices emerge.

In this note, I argue that the pandemic will also be remembered as a watershed moment for demographic research, and the point of rapid acceleration of already existing trends in population studies. These include: rethinking the temporal and spatial scale at which population processes operate; combining heterogeneous data sources, including privately owned ones, with solid statistical methods and research design; and assessing the growing importance of digital connections for social and generational relationships and as determinants of health and inequalities. More broadly, the pandemic has highlighted strengths, as well as revealed inadequacies, in our theoretical understanding of demographic processes, and represents a unique opportunity for theoretical advances in the discipline.

At the foundation of modern demographic research lies the belief that population processes unfold slowly and in fairly predictable ways. Regularities in demographic rates by age, sex, and over time are what makes mediumrange forecasts possible (Lee and Carter 1992; Schmertmann et al. 2014). The relative smoothness of demographic rates also informs the type of collection, processing, and distribution of data that happens at national statistical offices and international organizations. Most population statistics are produced at the country level, for one- or five-year periods, and are often published with substantial delays. The pandemic has forced us to rethink the temporal and spatial scales at which demography operates. As weekly excess deaths have

Emilio Zagheni, Max Planck Institute for Demographic Research.

POPULATION AND DEVELOPMENT REVIEW I ESSAYS (FEBRUARY 2021) 
become one of the key metrics of impact of the pandemic across countries (National Academies of Sciences, Engineering, and Medicine 2020), statistical offices quickly adjusted to address new needs. Overnight, demography went from "slow" to "fast" mode as more and more statistical offices reported time series of weekly deaths, in some cases disaggregated by age and sex, or at the subnational level. This rapid response will have long-lasting consequences on how demographers think about the time scale of population processes, and the type of data they produce and use.

Data with high temporal and spatial resolution have always been of interest to demographers. For example, highly granular data are important for assessing seasonality in demographic events (Dorélien 2016), the impact of natural disasters on mortality (Zagheni et al. 2015), the potential role of climate change on migration (Hauer 2017), or the consequences of conflict for fertility (Fargues 2000). Today, we have reached a level of interest in high-resolution data that we have never seen before. The scale of interest and relevance has moved from local settings to a global context. I believe that we are at a tipping point: as more and more institutions have invested resources in producing and releasing weekly mortality reports, and as network effects put pressure on institutions that have not been ready to adapt yet, we will see more and more timely dissemination of death records. This direction will also set a path beyond mortality statistics, and for countries that still have to develop capacity to meet current and future needs. This is not only momentum: it is a corollary of the fact that demographic measures, including mortality, fertility, and migration rates, have been recognized as important indicators of the state of our societies. For example, data compiled by the United Nations Population Division underpin about a third of the indicators used for monitoring the sustainable development goals globally. ${ }^{1}$ The growing importance of demographic data that are timely, highly granular, and open will serve as a rising tide for the whole discipline of demography. As more granular data will become available, more opportunities will emerge for solid causal analyses that will invigorate the field and strengthen demographic theory.

Established demographic data sources, like censuses, registers, and probabilistic surveys, are the polar star for population scientists and anchor demographers' orientation. However, in a growing number of cases, these sources are not enough to address today's challenges. The pandemic highlighted the increasing importance of data innovation, privately held infrastructure, and passively collected data. Web giants like Google, Facebook, and Apple have produced and maintained detailed aggregate-level geographic mobility reports, which are useful to assess, among others, the effect of nonpharmaceutical interventions on the spread of the pandemic (Ruktanonchai et al. 2020) and on mortality (Basellini et al. 2020). Online measurement companies for marketers, like Cuebiq, have made anonymous location data collected via apps available to researchers, as part of their "Data for Good" program. 
Some of these data have been used to calibrate epidemiological models (Pepe et al. 2020). Facebook ran a large-scale survey of its users to study Covid-19 symptoms, while demographers have used Facebook's advertisement platform to recruit survey participants (Perrotta et al. 2020). This explosion in data availability, as well as in the use of new types of tools and infrastructure for data collection, have highlighted challenges and opportunities ahead. On the one hand, in a crisis context, private companies showed increased willingness to share data responsibly and, to some extent, to shed light on the trove of information that is available to them. That said, these data cannot be taken at face value because of a number of inherent biases. However, when appropriately combined with representative sources and credible statistical methods, they become an invaluable asset for demographic research. For example, according to the World Health Organization, globally two-thirds of deaths are not registered with local authorities. ${ }^{2}$ While, in the long-term, comprehensive registration systems would be the preferable solution, in the short- and medium terms, new forms of data collection and indirect methods that leverage the infrastructure of the digital age are key. Emerging networkbased approaches for the estimation of demographic quantities (Feehan and Cobb 2019) are likely to receive more attention and I expect that the pandemic will further spur a new wave of innovative approaches to produce the best possible estimates in traditionally data-poor contexts.

Digital trace data are not the result of the pandemic, but Covid-19 has likely changed the perception that companies, scholars, and professional organizations have of these data, thus opening new opportunities for progress. Some of the mixing between industry and academia, along with a realignment of incentives, is likely to have planted the seeds for new forms of joint ventures. If appropriate measures are developed to guarantee privacy, dataprotection, and ethical frameworks for the use of digital traces, the pandemic may mark a milestone for the rapid acceleration of partnerships between scientists and holders of private data and infrastructure.

The rapid increase in data availability, often referred to as the "data revolution," is only the aftershock of deeper tectonic shifts in the way we live and interact with others in the digital age. As of 2019,81 percent of the adult population in the United States owned a smartphone, up from 35 percent in $2011 .{ }^{3}$ Worldwide, more than 4 billion people are estimated to use the Internet, up from less than 2 billion people a decade ago. ${ }^{4}$ The pandemic has forced more people to engage more deeply with the digital world, with long-term consequences. During lockdowns, communications with colleagues, friends, and members of the extended family took a digital form, for those who had the skills and resources to access digital technologies. As we tried to make sense of the world outside our homes, we turned to Google, Bing, Baidu, or alternative search engines. Daily activities like shopping for groceries moved online for many people. And so did many other aspects of our lives like at- 
tending lectures in school or college, consulting a physician, holding family events, dating, working, filing for unemployment, interviewing for a job, and virtually everything that could be moved online.

As social relationships were forced to become digital, we developed a new perception of the online world and its communities. The distinction between online and offline has become more blurred. This has important consequences for our societies and, as a result, for the research landscape in the social sciences. For instance, in public health there have been increased calls for fully considering broadband Internet access as a social determinant of health (Benda et al. 2020). This is consistent with an emerging line of research that aims at assessing the role of changes in information and communication technologies on development (Rotondi et al. 2020), demographic indicators (Billari et al. 2019), health and well-being (Lohmann and Zagheni 2020), and intergenerational relationships (Gil-Clavel and Zagheni 2019; Arpino et al. 2020). Demographers are uniquely positioned to quantify the demographic differential impact of access and use of digital technologies.

The pandemic is likely accelerating underlying trends in demographic research. While this indicates a bright future for population studies, Covid-19 is also shaking some of the pillars on which the discipline rests and exposing some inadequacies of current paradigms. One of the strengths of demography is that it relies on unambiguous definitions of the underlying events of interest. Births and deaths are clearly identified occurrences. However, most demographic measures, like rates, rely also on denominators that include population counts or related quantities, like person-years of exposure. These denominators are typically derived from concepts like the usual place of residence, and should account for migration and relocations. While migration is already particularly difficult to quantify, the pandemic has further challenged our ability to measure usual place of residence, as an increasing number of people have started to work remotely and often relocated temporarily to areas farther away from the usual workplace, sometimes across political borders. Measurement issues related to migration (Deville et al. 2014; Fiorio et al. 2017) will likely become more central for demography as they are crucial not only to understand migration trends, but also to produce accurate estimates of fertility and mortality rates, as well as health indicators, at various levels of spatial and temporal granularity.

A perhaps underappreciated strength of demography is that the toolbox of formal demographers is key to model and quantify a wide range of population issues, from the spread of the virus to the extent of excess deaths, and likely scenarios for the future. As a matter of fact, one of the most elegant theories of formal demography, the stable population theory, is closely linked to compartmental models used in epidemiology, and shares key concepts, like the intrinsic population growth rate, which is closely related to the R0, the 
basic reproduction ratio used in models for the spread of infections. While the pandemic reminded the world of the importance of formal demography, it also showed how much uncertainty there is about the long-term consequences of this shock on key components of demographic change, like fertility (Aassve et al. 2020) and migration (Guadagno 2020, O'Brien and Eger 2020). Existing theories provide insights and perspectives, but they remain largely fragmented and may lead to quite different conclusions. Major theories in demography, like the demographic transition theory, describe moves from disorder to stability (Livi-Bacci 2017). However, in contemporary societies we often encounter moves from order to disruptions, related to recessions, conflicts, famines, natural disasters, technological transformations, pandemics, and more.

While each shock is unique in some ways, compiling and analyzing disruptions and their impact on populations could hold the key to reconciling existing theories and formulating a synthesis of our understanding of the relationships between discontinuities and demography. One of the long-lasting consequences of the pandemic might be an increased awareness that, also in the context of demographic theory, we need the whole to become greater than the sum of its parts.

\section{Notes}

1 https://www.un.org/development/ $\mathrm{desa} / \mathrm{pd} /$ themes/sustainable-development.

2 https://www.who.int/news-room/factsheets/detail/civil-registration-why-countingbirths-and-deaths-is-important.

3 https://www.pewresearch.org/internet/ fact-sheet/mobile/.

4 https://www.itu.int/en/ITU-D/Statistics/Pages/stat/default.aspx.

\section{References}

Aassve, A., N. Cavalli, L. Mencarini, S. Plach, and M.L. Bacci. 2020. "The COVID-19 pandemic and human fertility," Science 369(6502): 370-371.

Arpino, B., M. Pasqualini, V. Bordone, and A. Solé-Auró. 2020. “Older people's non-physical contacts and depression during the COVID-19 lockdown," The Gerontologist.

Basellini, U., D. Alburez-Gutierrez, E. Del Fava, D. Perrotta, M. Bonetti, C.G. Camarda, and E. Zagheni. 2020. "Linking excess mortality to Google mobility data during the COVID-19 pandemic in England and Wales," SocArxiv.

Benda, N.C., T.C. Veinot, C.J. Sieck, and J.S. Ancker. 2020. “Broadband Internet access is a social determinant of health!" American Journal of Public Health.

Billari, F.C., O. Giuntella, and L. Stella. 2019. “Does broadband Internet affect fertility? Population Studies 73(3): 297-316.

Deville, P., C. Linard, S. Martin, M. Gilbert, F.R. Stevens, A.E. Gaughan, V.D. Blondel, and A.J. Tatem. 2014. "Dynamic population mapping using mobile phone data," Proceedings of the National Academy of Sciences 11 1(45): 15888-15893.

Dorélien, A.M. 2016. "Birth seasonality in sub-Saharan Africa," Demographic Research 34: 761-796. 
Fargues, P. 2000. “Protracted national conflict and fertility change: Palestinians and Israelis in the twentieth century," Population and Development Review 26(3): 441-482.

Feehan, D.M. and C. Cobb. 2019. "Using an online sample to estimate the size of an offline population," Demography 56(6): 2377-2392.

Fiorio, L., G. Abel, J. Cai, E. Zagheni, I. Weber, and G. Vinué. 2017. "Using Twitter data to estimate the relationship between short-term mobility and long-term migration," in Proceedings of the 2017 ACM on Web Science Conference (pp. 103-110).

Gil-Clavel, S. and E. Zagheni. 2019. "Demographic differentials in Facebook usage around the world. in Proceedings of the International AAAI Conference on Web and Social Media (Vol. 13, pp. 647-650).

Guadagno, L. 2020. "Migrants and the COVID-19 pandemic: An initial analysis," International Organization for Migration, Migration Research Series (60).

O'Brien, M.L. and M.A. Eger. 2020. "Suppression, spikes and stigma: How COVID-19 will shape international migration and hostilities toward it," International Migration Review.

Hauer, M.E. 2017. "Migration induced by sea-level rise could reshape the US population landscape," Nature Climate Change 7(5): 321-325.

Lee, R.D. and L.R. Carter. 1992. "Modeling and forecasting US mortality," Journal of the American Statistical Association 87(419): 659-671.

Livi-Bacci, M. 2017. “A Concise History of World Population.” John Wiley \& Sons.

Lohmann, S. and E. Zagheni. 2020. “Multi-platform social media use: Little evidence of impacts on adult well-being," Max Planck Institute for Demographic Research. Working paper.

National Academies of Sciences, Engineering, and Medicine. 2020. "Evaluating data types: A guide for decision makers using data to understand the extent and spread of COVID-19." Washington, DC: The National Academies Press.

Pepe, E., P. Bajardi, L. Gauvin, F. Privitera, B. Lake, C. Cattuto, and M. Tizzoni. 2020. “COVID-19 outbreak response, a dataset to assess mobility changes in Italy following national lockdown," Scientific Data 7(1): 1-7.

Perrotta, D., A. Grow, F. Rampazzo, J. Cimentada, E. Del Fava, S. Gil-Clavel, and E. Zagheni. 2020. "Behaviors and attitudes in response to the COVID-19 pandemic: Insights from a cross-national Facebook survey. medRxiv.

Rotondi, V., R. Kashyap, L.M. Pesando, S. Spinelli, and F.C. Billari. 2020. "Leveraging mobile phones to attain sustainable development," Proceedings of the National Academy of Sciences.

Ruktanonchai, N.W., J.R. Floyd, S. Lai, et al. 2020. "Assessing the impact of coordinated COVID-19 exit strategies across Europe," Science 369(6510): 1465-1470.

Schmertmann, C., E. Zagheni, J.R. Goldstein, and M. Myrskylä. 2014. "Bayesian forecasting of cohort fertility," Journal of the American Statistical Association 109(506): 500-513.

Zagheni, E., R. Muttarak, and E. Striessnig. 2015. "Differential mortality patterns from hydrometeorological disasters: Evidence from cause-of-death data by age and sex," Vienna Yearbook of Population Research 47-70. 